\author{
Military Technical College \\ Kobry El-Kobbah, \\ Cairo, Egypt.
}

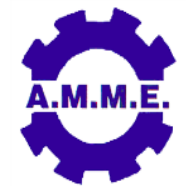
$18^{\text {th }}$ International Conference on Applied Mechanics and Mechanical Engineering.

\title{
TRANSIENT AND STEADY STATE PERFORMANCE CHARACTERISTICS OF A THERMOELECTRIC GENERATOR
}

\author{
A. S. El-Adl ${ }^{1}$, M. G. Mousa ${ }^{2}$, E. A. Abdel-Hadi ${ }^{3}$ and A. A. Hegazi
}

\begin{abstract}
The global energy and environmental issues are promoting the development of innovative energy solutions. Thermoelectric Generators (TEGs) are regarded as a promising alternative to conventional energy technologies. TEG is a device that converts thermal energy directly into electric power by exploiting Seebeck effect. In the present study, dynamic performance characteristics of a TEG are experimentally studied under different operating conditions. The effect of input heat rate and the influence of utilizing extended surfaces (fins) on both transient and steady state performance of a TEG are experimentally investigated. The variation in the temperature of the TEG hot and cold sides in addition to the output voltage is taken as a denotation of the performance characteristics. Input heat rate of $15.0 \mathrm{~W}, 17.5 \mathrm{~W}$, $20.0 \mathrm{~W}, 22.0 \mathrm{~W}$ and $25.0 \mathrm{~W}$ are applied to the TEG hot side. Free air convection (FC) is the utilized for heat dissipation from the TEG module through the cold side. From the experimentation, it can be deduced that increasing the input heat rate provides higher temperature difference across the module sides leading to higher power output. Additionally, using fins to aid heat dissipations enhanced the TEG performance by lowering the temperature of cold side and increasing the temperature difference across the module. The experimental data obtained are compared with the data available by the TEG module manufacturer and excellent agreement is obtained.
\end{abstract}

\section{KEYWORDS}

Thermoelectric generator (TEG), Seebeck effect, fins, temperature of the TEG sides, power output, conversion efficiency, transient and steady state performance.

1 Department of Mechanical Engineering, Higher Technological Institute, Tenth of Ramadan City, Egypt. Email Address: ahmed.eladl@hti.edu.eg.

2 Department of Mechanical Power Engineering, Mansoura University, Mansoura, Egypt.

3 Department of Mechanical Power Engineering, Benha University, Shoubra, Egypt. 


\section{NOMENCLATURE}

\begin{tabular}{|l|l|l|l|}
\hline $\mathrm{Bi}_{2} \mathrm{Te}_{3}$ & Bismuth Telluride & \multicolumn{2}{|l|}{ Greek symbols } \\
\hline $\mathrm{FC}$ & Free convection & $\Delta$ & Difference \\
\hline $\mathrm{k}$ & $\begin{array}{l}\text { Thermal Conductivity, (W/m } \\
\text { K) }\end{array}$ & $\eta$ & Efficiency, (\%) \\
\hline $\mathrm{n}$ & Negative & $\Omega$ & Ohm \\
\hline $\mathrm{p}$ & Positive & $\sigma$ & Electric conductivity, (S) \\
\hline $\mathrm{P}$ & Power & Subscript \\
\hline $\mathrm{Q}$ & Heat rate (W) & $\mathrm{c}$ & Conversion \\
\hline $\mathrm{R}$ & Electric resistance,(W) & $\mathrm{H}$ & Electric heater \\
\hline $\mathrm{S}$ & Seebeck coefficient, (V/K) & in & Input \\
\hline $\mathrm{T}$ & Absolute temperature, (K) & $\mathrm{L}$ & Load \\
\hline TEG & Thermoelectric generator & $\mathrm{O}$ & Output \\
\hline $\mathrm{V}$ & Voltage, (V) & \multicolumn{3}{|l}{} \\
\hline $\mathrm{ZT}$ & Figure of merit & \multicolumn{3}{|l}{} \\
\hline
\end{tabular}

\section{INTRODUCTION}

The acceleratory asymmetry between demand and provision supply of energy and continual energy abjection motivates the researchers to inquire environmental affable, clean energy resources. Thermoelectric devices are among the most promoting and cost-efficient energy resources. TEG provides versatile advantages over conventional power generators. TEG offers various advantages over traditional power generators. TEGs are robust solid-state energy converters that have no mechanical moving parts and hence are silent, lightweight, reliable, durable, compact, maintenance-free, long operating periods, uncomplicated scalability and environmentally friendly. The use of TEGs has increased rapidly in recent years with applications ranging from microwatts to kilowatts. One of the most important applications is the recovery of waste heat from industrial processes [1], as well as the recovery of automotive waste heat [2]. In addition, TEGs can be used to produce electricity by direct conversion of renewable energy such as solar energy [3]. Moreover, due to their robustness, thermoelectric generators are suitable for specialized applications such as aerospace, medical, military and telecommunications [4]. A typical TEG module consists of a number of semiconductor pairs. Each pair includes a "p-type" (hole carriers) and an "n-type" (electron carriers) thermo elements (i.e., pellet) connected through metallic electrical contact pads, this pair is known as a thermoelectric couple (or thermocouple) which is shown in Fig. 1 [5].

In the module, thermocouples are connected electrically in series with metal connecting strips and thermal in parallel, sandwiched between two electrically insulating and thermally conducting ceramic plates. A cut-away view of a typical TEG module is shown in Fig. 2.

The efficiency of thermoelectric materials greatly depends on the figure of merit, ZT = $\frac{S^{2} \sigma}{k} T$, where "S" is the Seebeck coefficient, " $\sigma$ " is the electric conductivity, " $k$ " is the thermal conductivity, and " $\mathrm{T}$ " is the absolute temperature at which the properties are 
measured. [6]. Thermoelectric materials with high ZT values have been developed continuously [7-8]. In addition to exploring thermoelectric materials properties, optimizing the geometrical shape and design of thermoelectric module have been considered continuously [9-10].

Considerable research studies were also experimentally carried out to examine thermoelectric power generation and device efficiency. Sarhadi et al. [11] presented the influence of using different interface materials on power-producing capabilities of a TEG as a function of flow rate. Three different thermal interface materials were assessed. The optimal thermal interface material was shown to be graphite paper. The influence of metal foams on the performance of thermoelectric waste heat recovery system was experimentally investigated by Wang et al. [12]. The results showed that filling metal foams in the flow channels could efficiently enhance the performance of the TEG. A comparison between the thermal performances of thermoelectric generators with the cold sides cooled by either bare plate, $60 \mathrm{~mm}$ fin, $80 \mathrm{~mm}$ fin and $100 \mathrm{~mm}$ fin is presented by Date et al. [13]. It was concluded that the increasing the fin length from $60 \mathrm{~mm}$ to $100 \mathrm{~mm}$ did not have as much effect on the cooling capacity and similarly did not had as much effect on power generation capacity from the thermoelectric generators. Montecucco et al. [14] analyzed the impact of thermal imbalance on the power produced from arrays of thermoelectric generators connected in series and parallel. The presented results suggested that series electrical connection enabled more of the available power to be captured. Thermoelectric power enhancement of a liquid-to-liquid TEG was investigated by Lesage et al. [15]. Three different geometric forms of flow turbulating inserts were fitted into the channels of the thermoelectric generator. Spiral inserts were shown to offer a minimal improvement in thermoelectric power production whereas inserts with protruding panels are shown to be the most effective. Rezania et al. [16] studied the power generated versus the coolant pumping power in the TEG. The results showed that there is a unique coolant flow rate at any temperature difference that makes maximum net-power in the system.

Concluding from the literature, there is a significant push to increase the output power of TEGs by enhancing their performance in order to make them more competitive energy technology. In the present study, the influence of different operating conditions on transient and steady state performance characteristics of a TEG are experimentally investigated. Operating aspects of the TEG system such as hot side temperature, cold side temperature, closed circuit voltage and power output are studied. The effect of input heat rates through the TEG hot side in addition to utilizing fins to aid heat dissipation from the module cold side on the TEG performance is experimentally demonstrated.

\section{EXPERIMENTAL SETUP AND PROCEDURE}

The experimental setup is designed and constructed to study the performance characteristics of the TEG for both transient and steady states are shown in Fig. 4. A thermoelectric Bismuth Telluride $\left(\mathrm{Bi}_{2} \mathrm{Te}_{3}\right)$ device designed for electric power generation, with a physical size of $62 \mathrm{~mm} \times 62 \mathrm{~mm} \times 4.0 \mathrm{~mm}$, containing $127 \mathrm{p}-\mathrm{n}$ couples connected in series has been used in this study. To provide the necessary thermal input to the device, the hot side was attached to a copper plate, heated with a nominal power of $277 \mathrm{~W}$. The rate of heat input is adjusted using an electrical 
autotransformer (VARIAC) connected to a voltage stabilizer to ensure constant input heat rate to the TEG. An assembly is created to house the TEG for the testing purposes. The assembly consists of two copper plates; one is placed between the heater and the hot side of the module, while the other plate is placed between the heat sink and the cold side. These copper plates are chosen for construction due to its high thermal conductivity, so heat is well distributed and thus temperature measurements of both sides more convenient. The copper plates are insulated by Phenolic Laminated sheets (for electric and thermal insulation), where groves are made in these sheets to occupy the copper plates. The lateral area of the test section is heavily insulated with a thick layer of glass wool (excluded from Fig. 3) to prevent the heat loss from the test section to the surrounding. To ensure a proper thermal contact and minimum contact resistance, optimum-clamping force (i.e. as provided by module manufacturer) is applied on the TEG using screws and nuts. Additionally, a layer of thermal interface material is applied between the copper plates and both sides of the TEG. Both hot and cold sides temperatures are measured using ten Chromel (Nickel-Chromium Alloy) / Alumel (Nickel-Aluminum Alloy) thermocouples (type $\mathrm{K}$ ) with $0.2 \mathrm{~mm}$ wire diameter, where five thermocouples are used for each side. The two terminals of the TEG are connected with a non-inductive power resistor $(0.47 \Omega)$ to form an electric circuit from which the output voltage and power output could be accurately measured. The temperature of module sides in addition to the output voltage is recorded using a data acquisition system model $\mathrm{NI} \mathrm{PCl-6013,}$ manufactured by National Instruments $\mathrm{Co}$. Also, all the thermocouples are connected to temperature recorder through a multi-switch arrangement. The uncertainty in temperature measurements was $\pm 1.5^{\circ} \mathrm{C}$. The utilized fins consist of 15 fins with 2 $\mathrm{mm}$ thickness and $16 \mathrm{~mm}$ height. The gap between the fins is $2 \mathrm{~mm}$. Also, a layer of thermal interface material is placed between the fins and the upper surface of the cold side copper plate to ensure good contact between them. The fin is clamped over the copper plate through the usage of a pin - screw fixture threaded through two holes machined in the upper Phenolic Laminated sheet. The surrounding temperature is maintained at $30^{\circ} \mathrm{C}$ during all experiments.

\section{DATA REDUCTION}

The experimental data obtained from the hot side temperature, cold side temperature, and output voltage is used to calculate the power output and conversion efficiency. At steady state condition, the produced heat generated by the electrical heating is given by the equation:

$$
\mathrm{Q}_{\text {in }}=\left(\frac{\mathrm{V}_{\mathrm{H}}{ }^{2}}{\mathrm{R}_{\mathrm{H}}}\right)
$$

where " $Q_{\text {in }}$ " is the heat generation rate supplied by electric heaters $(W)$, " $V_{H}$ " is the applied voltage across the electric heater terminals (Volt) and $R_{h}$ is the heater resistance $(\Omega)$.

The power output from the TEG can be derived from the following equation:

$$
\mathrm{P}_{\mathrm{O}}=\left(\frac{\mathrm{V}_{\mathrm{o}}{ }^{2}}{\mathrm{R}_{\mathrm{L}}}\right)
$$


where "Po" is the power output $(\mathrm{mW})$, " $\mathrm{V}_{\mathrm{o}}$ " is the output voltage $(\mathrm{mV})$ and " $\mathrm{R}_{\mathrm{L}}$ " is the load resistor $(\Omega)$.

By measuring the power output of the TEG through a load, the conversion efficiency can be calculated as follow:

$$
\eta_{\mathrm{c}}=\frac{\mathrm{P}_{\mathrm{o}}}{\mathrm{Q}_{\mathrm{in}} \times 10^{3}}
$$

where " $\eta_{c}$ " is the conversion efficiency (\%).

\section{RESULT AND DISCUSSION}

In experimental results, the effect of different operating conditions on both transient and steady state performance of the TEG module is presented. A comparison between the present experimental data of the variation in the power output with hot side temperature and those reported by the manufacturer [17] in case of FC assisted by fins as a heat dissipation technique is illustrated in Fig. 4. An excellent agreement can be observed between both results, concluding that the power output increases almost linearly with increasing the hot side temperature.

The coincident between the obtained experimental data and those from the manufacturer indicates the validity of the experimentation procedures applied and the accuracy of measurement. The slight discrepancies (i.e. within $2.5 \%$ ) both results can be attributed to the difference between the used measurement techniques in the present study and that of used by the manufacturer.

The effect of input heat rate on the variation of both sides temperature with time in case of FC is illustrated in Fig. 5. Figures $5 \mathrm{a}$ and $5 \mathrm{~b}$ show the variation of the temperatures with time for the hot side and cold sides without and with fins for various values of input heat rate, respectively.

From these preceding figures, it can be concluded that for all the operating conditions in the experimental studies, the temperature of both sides increases with increasing the input heat rate, whereas the system heats up relatively quickly in the beginning and then slowly converts to steady state operation. Additionally, by comparing the temperatures of both sides for all operating conditions studied, it can be deduced that the temperature of the cold side is always lower than that of the hot side. This is related to the cooling effect provided by heat dissipation. In addition, it can be noticed that the temperature of both sides follows the same trend of transitory increase with operating time and until steady state is achieved. This occurrence is caused by the direct effect of heat conduction through the module from the hot side to the cold side. So the thermal conductivity of an excellent thermoelectric material should be relatively low so that a temperature difference can be established and maintained across the module. It is worthy to note that in addition to the effect of heat conduction (i.e., Fourier's heat), the temperature of both sides is also affected by Peltier effect, Joule heating and Thomson effect, which occur when a current flows through the module due to the connection of a load to the TEG output terminals. 
The effect of input heat rate on the variation in the output voltage with time, in case of $\mathrm{FC}$, is shown in Fig. 6 . Figures $6 \mathrm{a}$ and $6 \mathrm{~b}$ demonstrate the variation of output voltage with time, in case of FC without and with the aid of fins, respectively for various values of input heat rate.

According to Seebeck effect, TEG produces a voltage when a temperature gradient is established at its sides. Increased inward heat rate at the TEG hot side allows for a much higher temperature gradient across the module and hence increased output voltage generation. This, in turn, improves the power output, which can be noticed from the figures mentioned above. At the start of TEG operation, the temperature difference between the two sides is zero that accordingly will lead to zero output voltage to be generated from the TEG (i.e., zero power output). With the transient time increasing, the temperature difference across the module increases with step trend due to quasi-steady thermal response and until the steady state operation is achieved. Additionally, it can be observed from Figs. 4 and 5 that the output voltage and the temperature difference between both sides are almost synchronously achieved stability. Steady state performance is used to summarize and clarify the obtained results.

The effect of input heat rate on the temperature of TEG for both the hot side and cold side is illustrated in Fig. 7. Figures $7 \mathrm{a}$ and $7 \mathrm{~b}$ show the variation in the temperature of both sides with input heat rates, in case of FC without and with the aid of fins, respectively. Generally, it can be deduced from the figures that the temperature of both sides varies almost linearly with input heat rate. Where the temperature of the hot side and the cold side is directly proportional to the value of input heat rate and the temperature of the cold side is intuitively lower than the temperature of the cold side due to the effect of heat dissipation causing the temperature difference between both sides.

The effect of input heat rate on the output voltage and the corresponding power output of TEG is shown in Fig. 8. Figures $8 \mathrm{a}$ and $8 \mathrm{~b}$ show the variation in the output voltage and the corresponding power output in case of FC without and with the aid of fins for various input heat rates, respectively. It can be illustrated that the output voltage and consequently the power output is directly proportional to the value of input heat. Increasing the input heat rate will stimulate the temperature difference across the TEG, by increasing the temperature of the hot side that in turn causes a higher output voltage and subsequently enhanced power output. Additionally, it can be noticed that both output voltage and power output follow the same trend for all studied cases. This intuitively returns to the dependency of power output on the output voltage.

The effect of utilizing fins to aid heat dissipation from the module on the temperature of the TEG hot and cold sides is shown in Fig. 9. It can be noticed that using fins with the TEG lowers the temperature of both TEG sides by enhancing the rate of heat transfer from the module cold side promoted by increasing the convective heat transfer area subjected to surrounding heat sink. This leads to a higher temperature difference across the TEG with an average increase of $4.8 \%$ up to $5.7 \%$.

The effect of input heat rate on the output voltage and power output is shown in Fig. 10. Figures $10 \mathrm{a}$ and $10 \mathrm{~b}$ show the variation in the output voltage and the corresponding power output for various input heat rates, respectively. 
Since utilizing fins to aid heat transfer from the TEG causes higher temperature difference across the TEG sides it will subsequently improve the output voltage, and in turn, the power output is enhanced with an average increase of 14.9 to $17.3 \%$.

The effect of using fins on the conversion efficiency is shown in Fig 11. It can be concluded that the increasing input heat rate will motivate the TEG to generate more output voltage that consequently will increase the power output and promotes, in turn, the acquisition of higher conversion efficiency. Since the conversion efficiency is defined as the ratio between the power outputs from the TEG to the rate of heat input, it can be expected that the enhancing effect caused by the utilization of fins on power output for the same input heat rate will consequently improve the conversion efficiency causing an average increase of $14.3 \%$ up to $18.4 \%$.

\section{CONCLUSION}

In the present study, an experiential investigation on the transient and steady state performance characteristics of a TEG is carried out. The effect of varying the input heat rate to the TEG hot side in addition to the effect of utilizing fins to aid the heat dissipation by free air convection from the TEG cold side on the performance is enquired. Based on the obtained results of the present study, it can be deduced that increasing the input heat rate causes an increase in both the hot and the cold sides temperatures as well as increasing the temperature difference. Hence, according to the Seebeck effect, the output voltage increases, leading to an increase in the power output and accordingly increases the conversion efficiency. In addition, it was observed that utilizing fins to aid heat rejection from the TEG causes an average increase of $14.9 \%$ up to $17.3 \%$ in power output. This is attributed to the reduction in the temperature of cold side, which leads to a higher temperature difference between the module sides, improves the generated output voltage, consequently increases the power output and enhances the conversion efficiency. An average increase of $14.9 \%$ up to $17.3 \%$ in conversion efficiency is achieved by utilizing fins to aid heat rejection from the TEG. A maximum conversion efficiency achieved was $5.8 \%$ in case of $25.0 \mathrm{~W}$ input heat rate and utilizing the fins to aid heat dissipation from the module.

\section{REFERENCES}

[1] Ding L., Meyerheinrich N., Tan L., Rahaoui K., Jain R. and Akbarzadeh A., "Thermoelectric Power Generation from Waste Heat of Natural Gas Water Heater", Energy Procedia, Vol. 110, pp. 32-37 (2017).

[2] Kim T., Negash A. and Cho G., "Waste Heat Recovery of a Diesel Engine Using a Thermoelectric Generator Equipped with Customized Thermoelectric Modules", Energy Conversion and Management, Vol.124, pp. 280-286 (2016).

[3] Shafii M., Shahmohamadi M., Faegh M. and Sadrhosseini H., "Examination of a Novel Solar Still Equipped with Evacuated Tube Collectors and Thermoelectric Modules", Desalination, Vol. 382, pp. 21-27 (2016).

[4] Bobean C. and Valentina P., "The Study and Modeling of a Thermoelectric Generator Module", The $8^{\text {th }}$ international symposium on advanced topics in electrical engineering, (2013). 
[5] Jang J. and Tsai Y., "Optimization of Thermoelectric Generator Module Spacing and Spreader Thickness Used in a Waste Heat Recovery System", Applied Thermal Engineering, Vol. 51, pp. 677-689 (2013).

[6] Barma M., Riaz M., Saidur R. and Long B., "Estimation of Thermoelectric Power Generation by Recovering Waste Heat From Biomass Fired Thermal Oil Heater", Energy Conversion and Management, Vol. 98, pp. 303-313, (2015).

[7] Du H., Su T., Li H., Li S., Hu M., Liu B., Ma H. and Jia X., "Enhanced Low Temperature Thermoelectric Performance and Weakly TemperatureDependent Figure-of-Merit Values of Pbteepbse Solid Solutions", Journal of Alloys and Compounds, Vol. 658, pp. 885-890 (2016).

[8] Li J., Li D., Qin X. and Zhang J., "Enhanced Thermoelectric Performance of P-Type Snse Doped With Zn", Scripta Materialia, Vol. 126, pp. 6-10 (2017).

[9] Cao Z., Koukharenko E., Tudor M., Torah R. and Beeby S., "Flexible Screen Printed Thermoelectric Generator with Enhanced Processes and Materials", Sensors and Actuators, Vol. A238, pp. 196-206 (2016).

[10] Huang K., Li B., Yan Y., Li Y., Twaha S. and Zhu J., "A Comprehensive Study on a Novel Concentric Cylindrical Thermoelectric Power Generation System", Applied Thermal Engineering, Vol. 117, pp. 501-510 (2017).

[11] Sarhadi A., Bjørk R., Lindeburg N., Viereck P. and Pryds N. "A Thermoelectric Power Generating Heat Exchanger: Part II - Numerical Modeling and Optimization", Energy Conversion and Management, Vol. 119, pp. 481-487 (2016).

[12] Wang T., Luan W., Liu T., Tu S. and Yan J., "Performance Enhancement of Thermoelectric Waste Heat Recovery System by Using Metal Foam Inserts", Energy Conversion and Management, Vol. 124, pp. 13-19 (2016).

[13] Date A., Date A., Dixon C., Singh R. and Akbarzadeh A., "Theoretical and Experimental Estimation of Limiting Input Heat Flux for Thermoelectric Power Generators with Passive Cooling", Solar Energy, Vol. 111, pp. 201217 (2015).

[14] Montecucco A., Jonathan Siviter J. and Knox A., "The Effect of Temperature Mismatch on Thermoelectric Generators Electrically Connected in Series And Parallel", Applied Energy, Vol. 123, pp. 47-54 (2014).

[15] Lesage F., Sempels É. and Lalande-Bertrand N., "A Study on Heat Transfer Enhancement Using Flow Channel Inserts for Thermoelectric Power Generation", Energy Conversion and Management, Vol. 75, pp. 532-541 (2013).

[16] Rezania A., Rosendahl L. and Andreasen S., "Experimental Investigation of Thermoelectric Power Generation versus Coolant Pumping Power in a Microchannel Heat Sink", International Communications in Heat and Mass Transfer, Vol. 39, pp. 1054-1058 (2012).

[17] TEG (GM250-127-28-10) Manufacturer Datasheet, http://www.europeanthermodynamics.com. 


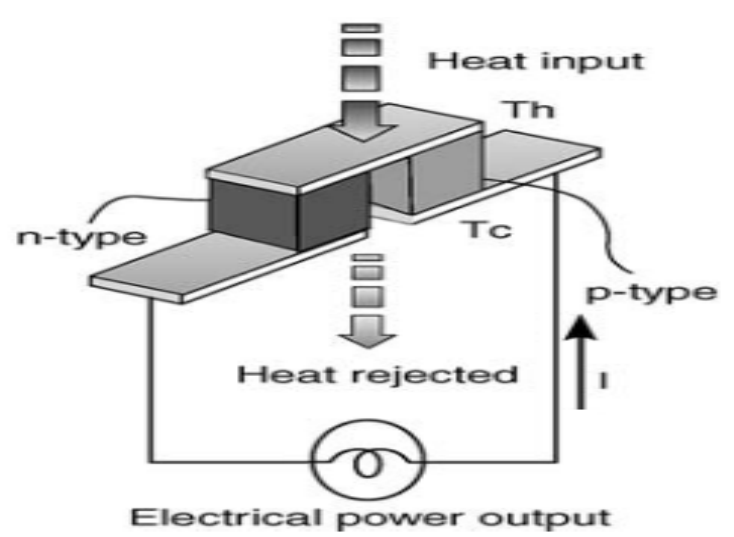

Fig. 1. Schematic diagram of a single thermoelectric couple (Thermocouple) [5].

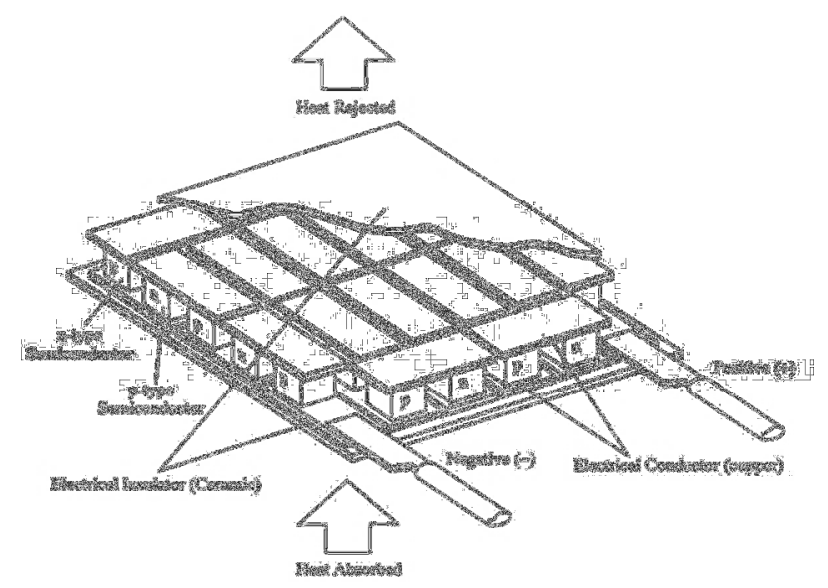

Fig. 2. Cut-away view of a typical TEG module [5].

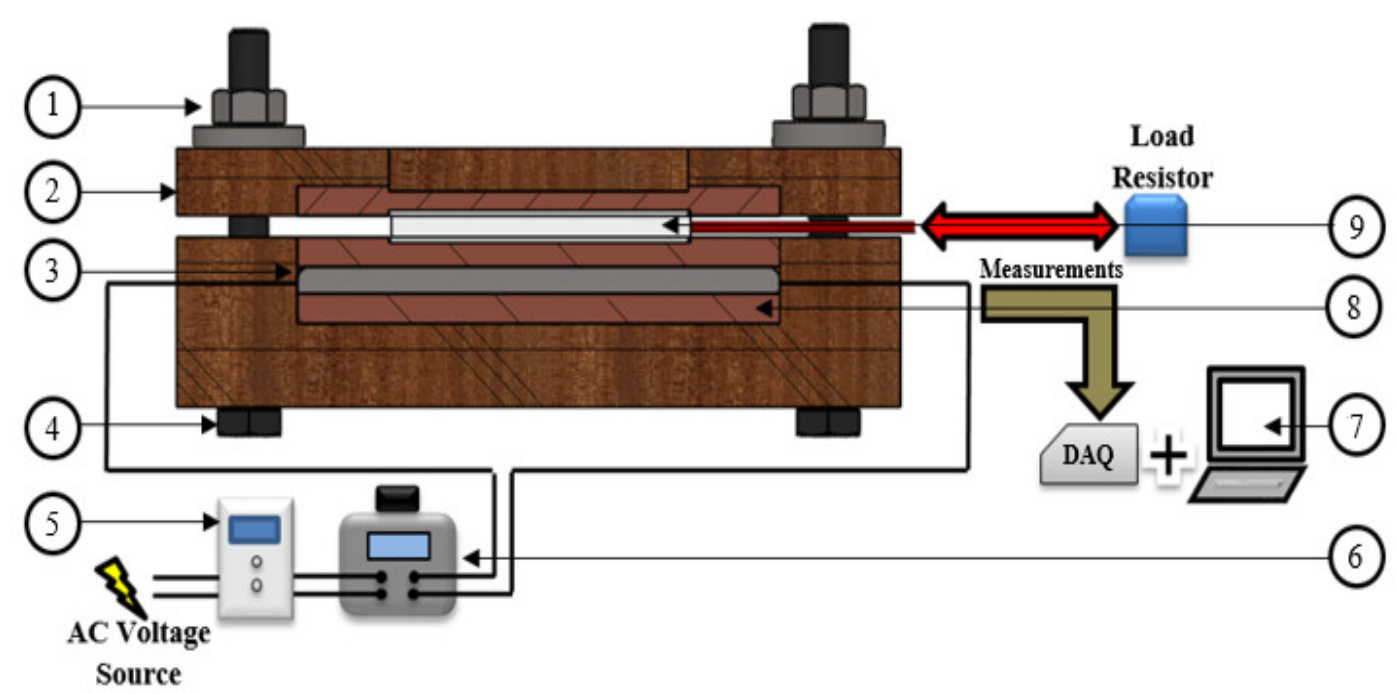

1. Nut, 2. Phenolic Laminated sheet, 3. Electric heater, 4. Screw 5. Voltage stabilizer, 6. Autotransformer (VARIAC), 7. Data acquisition system, 8. Copper plate, 9. TEG module.

Fig. 3. Schematic diagram of the experimental setup. 


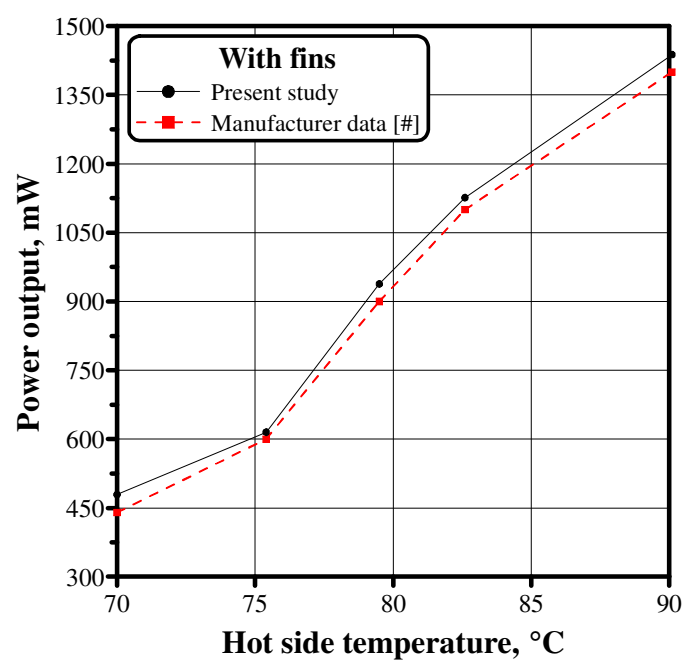

Fig. 4. Comparison between the present experimental results and that after reference [17], for the variation in the power output with hot side temperature.

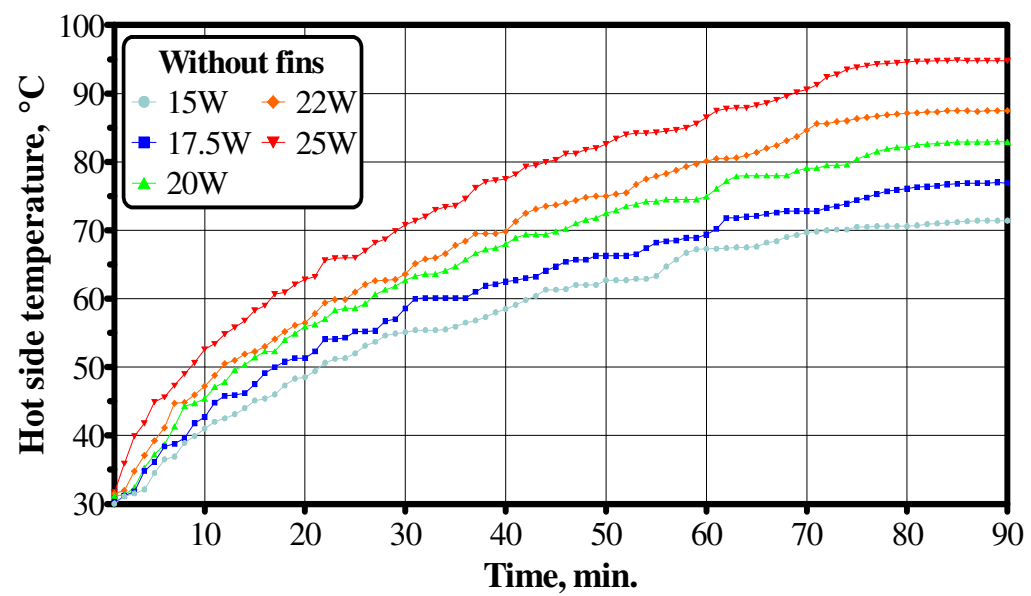

Fig. 5a. Variation in the hot side temperature with time for various input heat rates, in case of "FC" without the aid of fins.

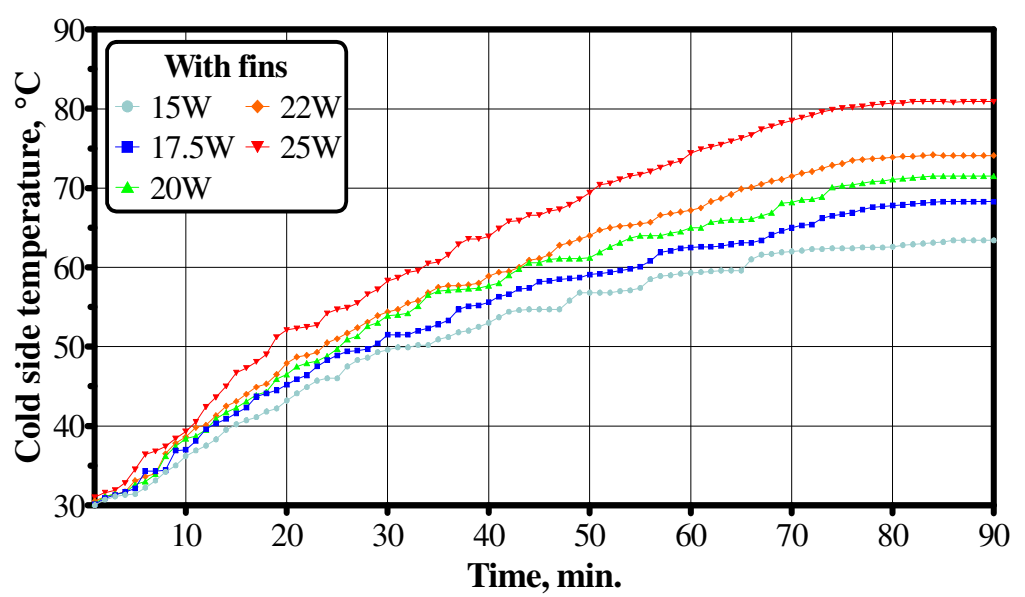

Fig. 5b. Variation in the cold side temperature with time for various input heat rates, in case of "FC" with the aid of fins.

Fig. 5. Effect of input heat rate on the variation in the temperature of both sides with time, in case of "FC". 


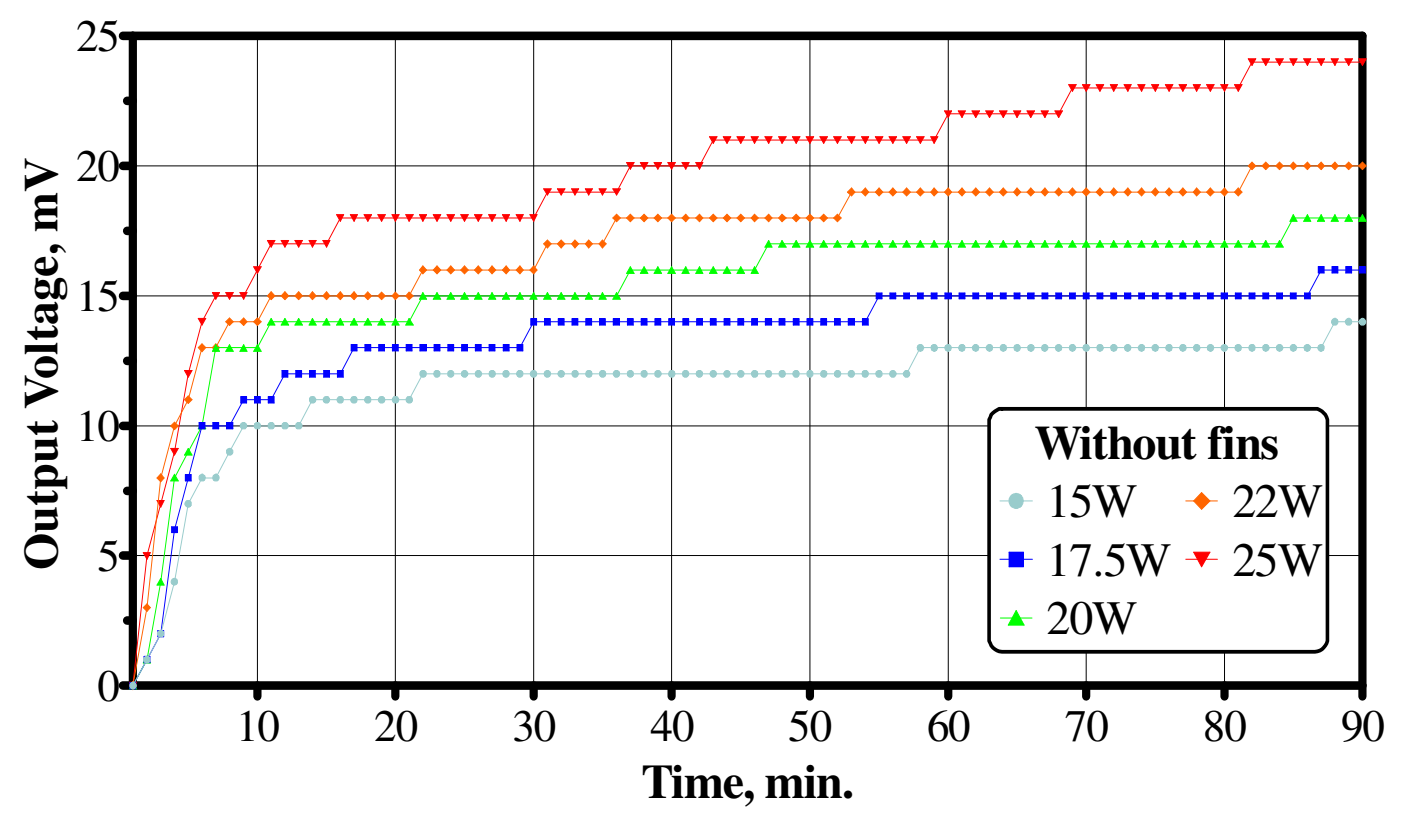

Fig. 6a. Variation in the output voltage with time for various input heat rates, in case of "FC" without the aid of fins.

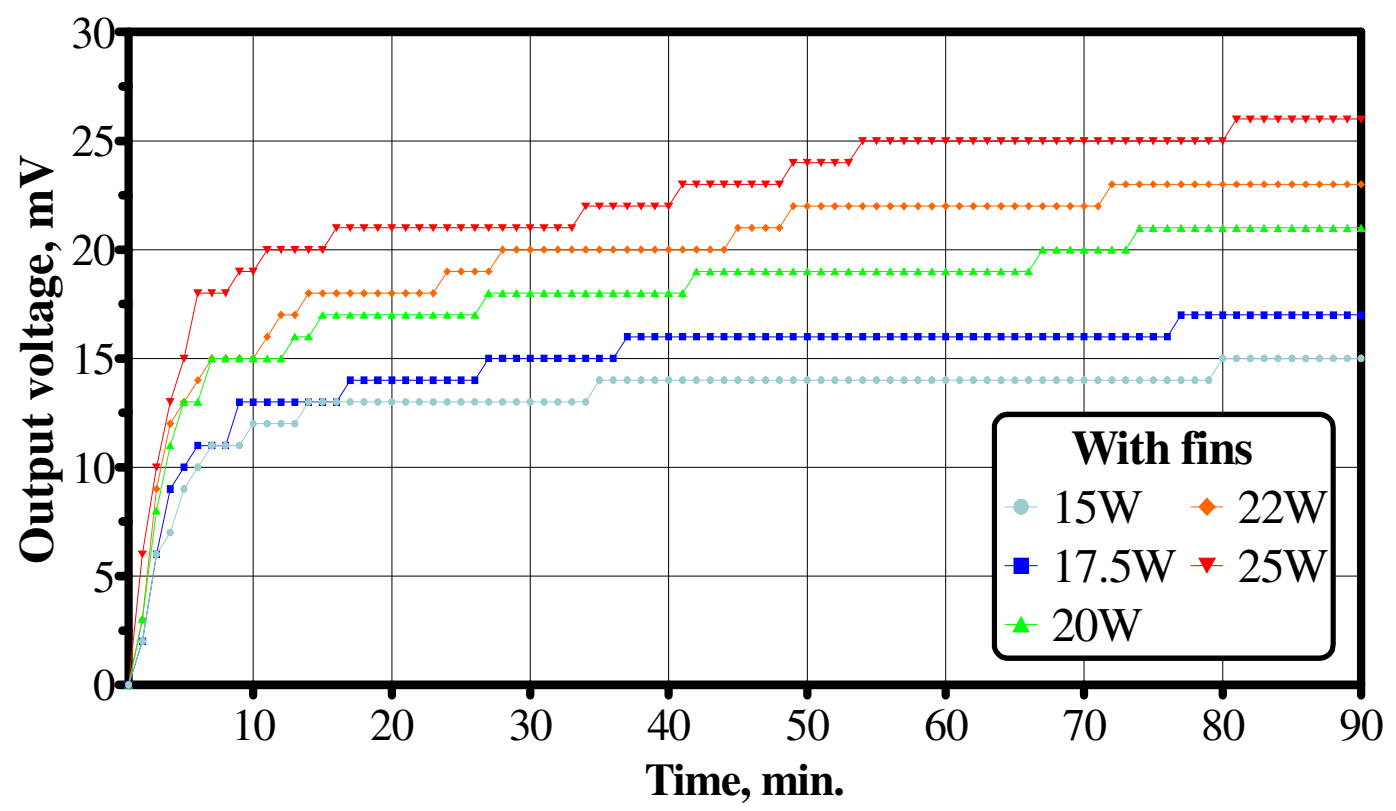

Fig. 6b. Variation in the voltage output with time for various input heat rates, in case of "FC" with the aid of fins.

Fig. 6. Effect of input heat rate on the variation in the output voltage with time, in case of "FC". 


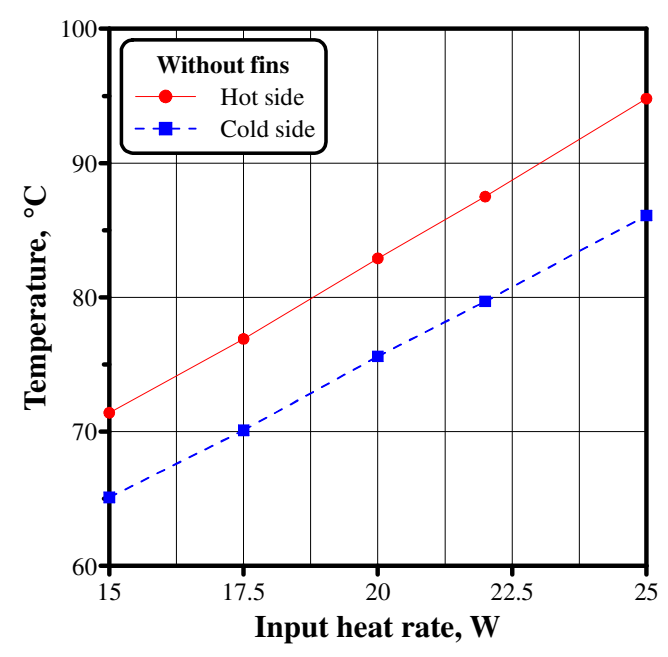

Fig. 7a. Variation in the temperature of both sides with input heat rate, without fins.

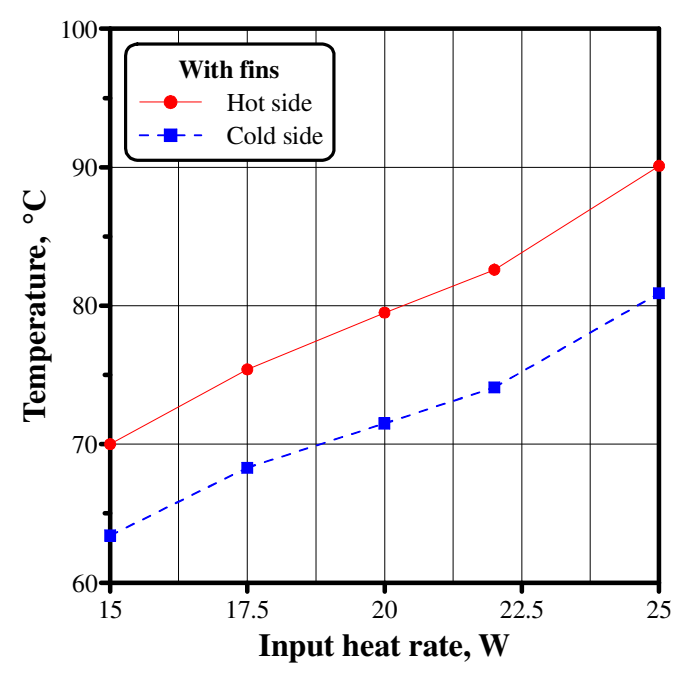

Fig. 7b. Variation in the temperature of both sides with input heat rate, with fins.

Fig. 7. Effect of input heat rate on the temperature of both sides.

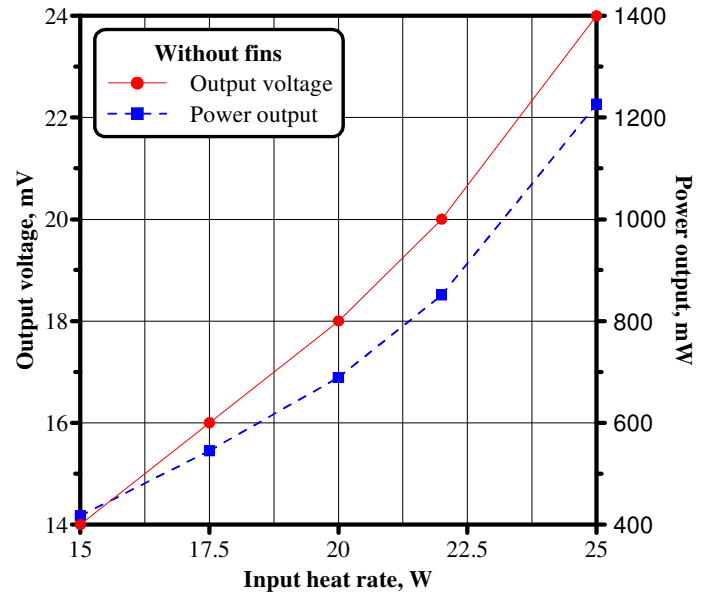

Fig. 8a. Variation in the output voltage and power output with input heat rate, without fins.

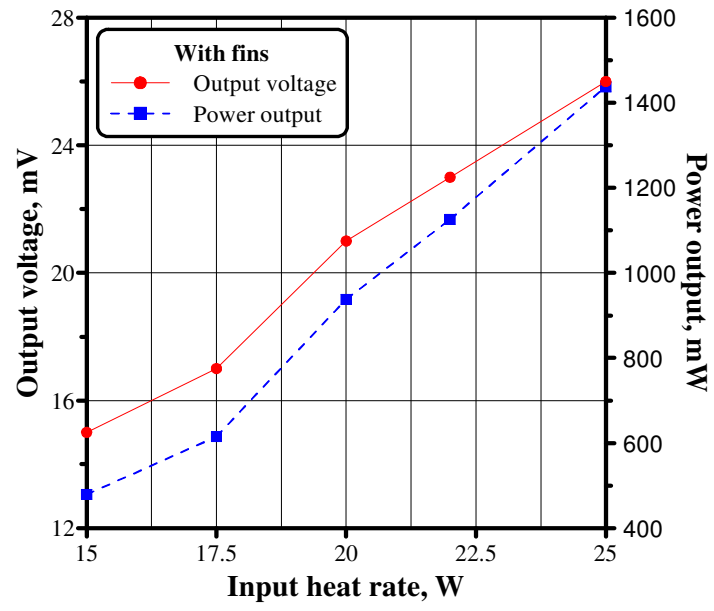

Fig. 8b. Variation in the output voltage and power output with input heat rate, with fins.

Fig. 8. Effect of input heat rate on the output voltage and power output.

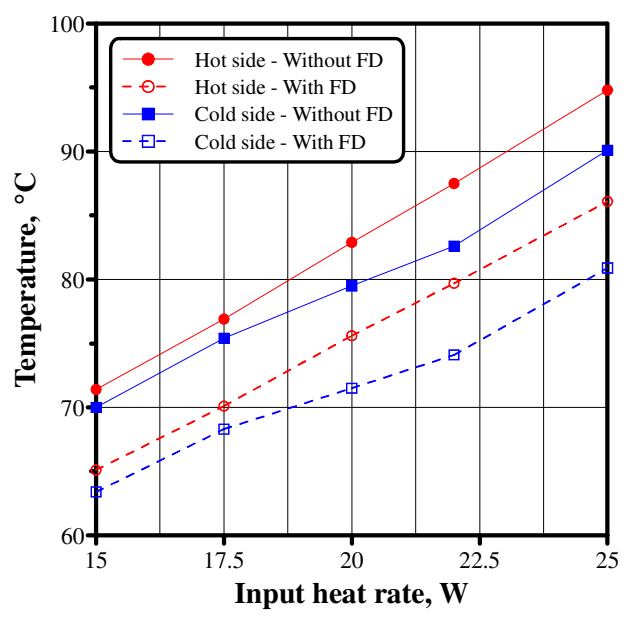

Fig. 9. Effect of using fins on the temperature of both sides. 


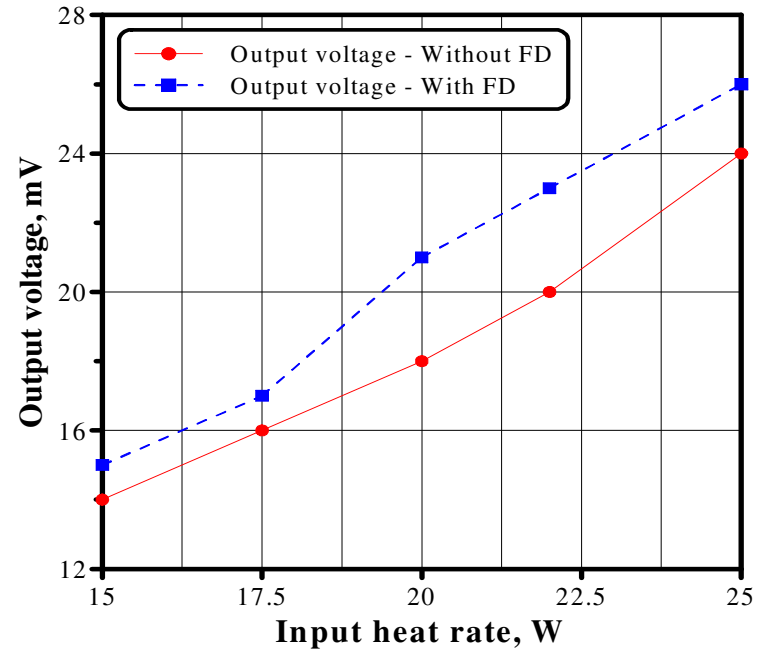

Fig. 10a. Variation in the output voltage with input heat rate.

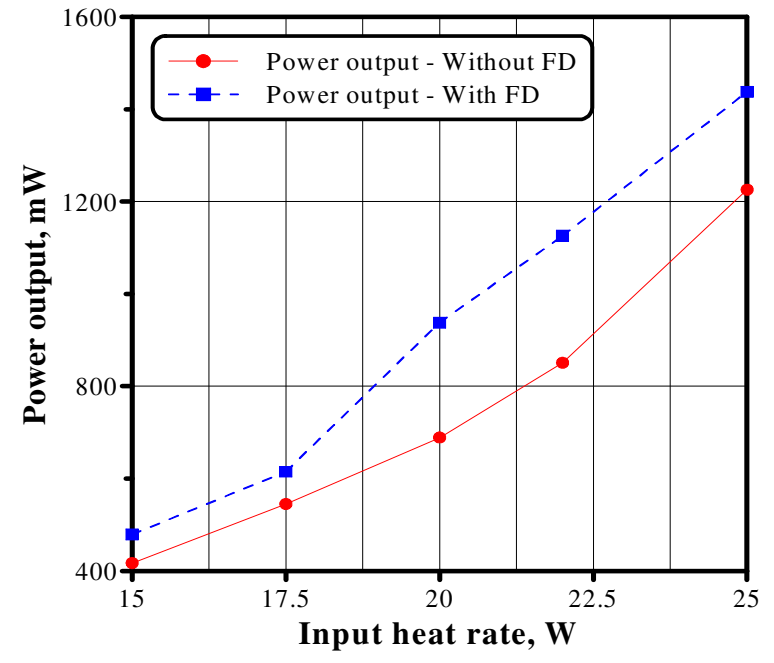

Fig. 10b. Variation in the power output with input heat rate.

Fig. 10. Effect of using fins on the output voltage and power output.

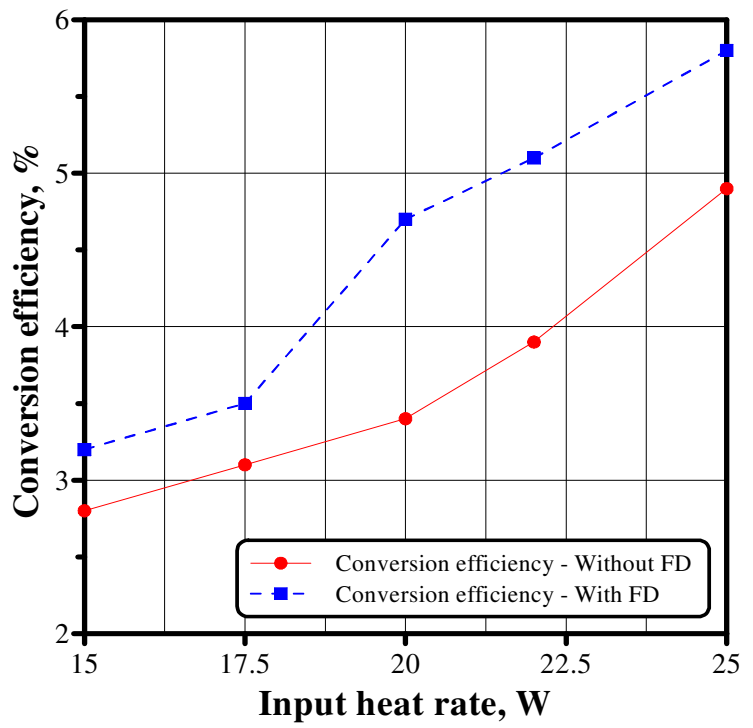

Fig. 11. Effect of using fins on the conversion efficiency. 